\title{
Consultation and involvement in the Library of Birmingham
}

\section{Clare Nankivell}

\begin{abstract}
Author
Clare Nankivell is Director, Centre for Information Research, Faculty of Computing, Information and English at the University of Central England. Clare is currently on secondment to Birmingham Libraries as Consultation and Involvement Officer on the Library of Birmingham Project.
\end{abstract}

\begin{abstract}
This paper outlines the role of consultation in the development of a new city centre library. The initial section focuses on the planning behind Birmingham City Council's project to replace its existing Central Library with a new Library of Birmingham on the other side of the city centre. The paper then goes on to discuss the role of public consultation in the early stages of this project, outlining the purposes, constraints, methods used, early findings and the longer-term ideas, questions and potential.
\end{abstract}

\section{Birmingham and its Central Library}

Birmingham's Central Library serves the largest number of people of any such library in the country and in its 30 years has been a growing and developing success. It serves a city population of around one million people, $30 \%$ of whom are from non-white ethnic minorities and has 5,000 visitors every week day and 2,000 visits per week from children. The Central Library houses the city archives and historic collections, including the internationally famous Boulton and Watt collections and the Shakespeare library, as well as other rare books and over 2 million photographs (http://www.birmingham.gov.uk/centrallibrary).

The Central Library is a success in supporting:

- $\quad$ education and lifelong learning

- improved quality of life, for example, through access to literature; creativity in reading, music and the performing arts; the story of Birmingham and its people, past and present; and the unique Centre for the Child

- $\quad$ business and enterprise, for example, 2,500 enquiries per week relate to these areas

- $\quad$ city centre life - it is open every weekday evening until 8pm and is a centre for family visits on Saturdays

- $\quad$ social inclusion, for example, $30 \%$ of users are from black \& ethnic communities, $13 \%$ of users have a declared disability, $20 \%$ of core users are retired, $10 \%$ of users are unemployed, and a third of adult users are young people under 24 years.

Despite these successes and although the present Central Library building is only 30 years old, it is no longer able to meet the city's needs, for seven key reasons: 


\section{Serious structural problems}

The building is suffering from carbonation (corrosion in its concrete) and is visibly crumbling. This problem started in the roof but has spread to all of the exterior walls and the library is now covered with protective netting to stop the concrete falling onto passers-by. The recently refurbished escalators have a 9-year guarantee, after which the City Council will need to replace them or find alternative means of access around the building. The library needs new boilers, heating and cooling systems.

\section{$2 \quad$ Access}

Access for people with disabilities is poor. Two particularly poor areas are access to the Archives department which is via a spiral staircase, stairs-only access to the lower ground floor and only one public lift to the other floors for 5,000 visitors a day.

\section{$3 \quad$ Space}

The existing Central Library is just under $25,000 \mathrm{~m}^{2}$ and has grown by $25 \%$ since first opening in 1974. However, there is not enough space in the library to store, display and make accessible all of its resources and expansion is not possible within this space constraint.

\section{The Archives and Historic Collections}

The present library building does not meet the required government standards (BS5454) for storage, preservation and access to archives, rare books and local records. The design and infrastructure of the existing Central Library are such that it would be extremely difficult and costly for the City Council to adapt it to improve the poor environmental conditions under which rare and valuable heritage resources are suffering. There is also insufficient space for housing and improving these important collections, for example, to develop exhibition and display facilities and to encourage more people to use and enjoy the special collections.

\section{$5 \quad$ Learning resources and facilities}

The Central Library was built primarily as a reference library and at a time when printed materials were almost the sole learning resource. Since then, technology has changed the way in which people access learning and support facilities and networked PCs and email are essential learning tools. The design and infrastructure of the Central Library make it very hard and potentially enormously costly for the City Council to further develop its ICT resources and tools to support learning and leisure.

\section{Sustainability}

The existing library has high running costs and is extremely inefficient in its use of energy. Measures to lower the costs and to make the building more energy efficient will cost significant amounts to establish.

\section{$7 \quad$ Funding}

Between $£ 14$ million and $£ 37$ million will need to be found to cover the costs of the essential and developmental work on the Central Library. The City Council does not have access to the funds required for this essential work.

These seven key problems in maintaining and developing the Central Library to meet the city's needs led the City Council to explore the option of a new city centre library. 


\section{The Library of Birmingham Project}

An in-depth feasibility study conducted in 2000, explored several potential sites for an expanded city centre library, including an extension to the existing Central Library to house the Archives and historic collections, adaptation of other city centre buildings, and new sites around the city. The Eastside area of the city centre was the only site large and flexible enough to take forward. This area has been designated as the Learning Quarter of the city and is a major regeneration initiative for Birmingham on the eastern edge of the City Centre, until recently cut off from the central areas by the inner ring road which has been demolished. For the City Council, it is hoped that the Library of Birmingham will contribute directly to the economic re-positioning of the city and encourage major investment in the regeneration area as well as support Birmingham in its ambitions to become the European Capital of Culture in 2008. For the Library service, the site offers the opportunity to meet the city's future needs of its central library and archive resources and services in an accessible environment at the heart of the learning Quarter and overlooking a new urban park.

In early 2002, Birmingham Libraries started work on the Library of Birmingham project. The early work of the project team included the development of a vision and models for the Library of Birmingham. This vision and its models outline the early thinking on the library of the future, its roles and functions (2002, Dolan, J and Khan, A). Other early work included consultation sessions with staff, drawing up a prospectus and the appointment, through an international selection process, of architects the Richard Rogers Partnership (http://www.rrp.co.uk ). The architect's brief was to produce a concept design for the Library of Birmingham by the end of November 2002. Alongside the work of the architects, a team working within the Library service was appointed to co-ordinate the project, to explore Heritage Lottery Funds to support the re-housing of the Archive and historic collections and to prepare the detailed brief for the architects. A cross-service team was also convened as the Consultation Steering Group to co-ordinate public consultation for the project, and a full-time consultation and involvement officer was appointed for a year in July 2002.

Consultation is key to any new development involving public services, and the Library of Birmingham project team is involved in consulting with staff, both within the Central Library and across community libraries, with organisations which might consider relocating to the city's Learning Quarter in Eastside alongside the library, as well as with the public. This paper concentrates solely on the public consultation programme.

\section{Public consultation: the background}

Prior to the consultation officer's appointment, the Consultation Steering Group had developed a consultation plan which included target groups, as well as potential consultation methods and events, and had identified personnel from within the Library service who could input to the public consultation programme. Clearly, not every individual in the city could be included in the consultation, but the process must ensure that all people had an opportunity to hear about the Library of Birmingham project and to contribute their views if they so wanted. Target groups for the public consultation were defined to help ensure that excluded communities were included in this process. Target groups were library users and non-users from the following:

- general public

- children, families and young people

- black and minority ethnic communities
- business sector

- people with disabilities

- older people 
The public consultation started with various given constraints and opportunities:

1. a site for the development had been selected via a feasibility study. As a brownfield site, it has specific environmental and building constraints which the architects would have to take into consideration in their building design.

2. the architects had been appointed to develop the concept design by the end of November 2002, so results were needed quickly to feed into their initial design work

3. an innovative and forward looking vision of Birmingham's city centre library of the future had been put forward

4. the Library of Birmingham was not 'a done deal' - the City Council had agreed to explore a concept design on the agreed site, which would provide further feasibility results on creating a new city centre library, including likely costs of the new building and public views of it. The City Council will only decide whether to go ahead with the building once work on the building design, costs and funds are completed and a business plan is accepted by them.

Consultation with the public was intended to build on the proposed vision, to feed into the architect's designs and to inform the ongoing development of the Library of Birmingham project. From July to November 2002, the consultation would be very open and would feed directly into the concept design which the architects were commissioned to produce. The questions would focus on what people like and do not like about the existing library and on what they would like the new library to look like, what kinds of materials should be used in its construction, and broadly what the library should feel like and 'do'. The concept design would be the first cut-off point in the Library of Birmingham project, since once it was accepted by the City Council, it would be the basic design for the new Library.

Therefore, from December 2002 to July 2003, the consultation would focus on this concept design, exploring what people like and don't like about it and what they would like to see happen within the library - services, facilities, resources and collections. Despite this split into two parts, many of the questions would remain the same throughout the year long consultation programme, as the interior design and the library purpose and services could be explored in both parts.

\section{Public consultation methods used}

Public consultation must always use a variety of methods and techniques, as different groups of individuals will respond best to different opportunities to have their say. At the outset of the consultation process, it was clear that combinations of written and spoken methods, formal and informal consultation and group and one-to-one sessions would be necessary to encourage responses from all types of people. The consultation plan was to target people through a variety of different types of venue too, taking the consultation out to people in their own settings (for example schools, youth clubs, local history group meetings, shopping centres and cultural events) as well as setting up events in the city's libraries specifically for the consultation process. It was originally anticipated that the consultation officer would spend half of her time on talking with the public.

The decision to use a broad range of consultation tools, methods and venues has been borne out by the consultation process. For example, one man has written a number of detailed 
letters to the Library of Birmingham team asking about various aspects of the project, as well as having written to the local press. Despite being invited to a number of formal and informal consultation discussions, he prefers to offer his views in writing only. Conversely, at various events where the Library of Birmingham has had a staffed information stand, people will refuse to take a postcard questionnaire to complete and return as they do not (for many different reasons) fill in forms, but are happy to talk about their views, desires and needs of the library service. Similarly, some people will stop and discuss the library plans informally, such as at the city's ArtsFest (a weekend of free arts and music events in the city centre), but would not attend a formal discussion group of any kind.

Examples of the consultation methods used to date include:

- Unsolicited - letters, emails and comment cards

- Library of Birmingham website questionnaire

- $\quad$ Postcard questionnaire survey distributed via all the city's libraries and at other venues and events

- Presentations and discussions at public workshops in the Central and community libraries

- Discussions with individuals attending the City Centre Discovery Day

- Birmingham ArtsFest stall and discussions with individuals

- Discussion with an adult dyslexia group

- Sustainability Forum presentation and discussions

- Discussions at Black History month events

- Message board discussion on the City Council website

- $\quad$ Presentations and discussions at Local History Group meetings

- Discussion groups in schools

- Young People's Parliament debate, presentations and workshops

- Discussion groups in Behavioural Support Centres

- Discussion groups in Youth clubs

- Questionnaire at "looked-after children day" (a day of activities for children and young person looked after by the local authority)

- Children's web questionnaire

- Comments on the Centre for the Child's Wall of wishes

- Interviews with home educated families

- Questionnaires distributed with the CIPFA Children's PLUS and Archive User Surveys.

Key tools and questions were developed at the outset of the consultation programme to ensure a consistency of approach to the consultation with all groups and individuals. A publicity brochure was produced and distributed to the city's libraries and other venues, along with a postcard questionnaire, a PowerPoint presentation was created to use when talking to groups, the Library of Birmingham website was established (www.birmingham.gov.uk/lob) and more 
detailed resources, such as the Prospectus, were available for people to request or download from the Internet.

There was, in fact, one key open question used in the early stages: "What would you like in the new library that would make you want to visit?". This question was used in all written consultation methods and asked of all discussion groups and in individual interviews. Leaving the question open helped to secure individual responses with no pre-set options to suggest certain ways of thinking. This has provided the Library of Birmingham team with masses of in-depth information on what people would like. Although analysis has taken longer than it would have using closed questions, the data received has been extremely high quality and reflects individual concerns of all those consulted. It also allowed aspects of this one broad question to be explored in discussion groups, such as what the exterior of the library should look like (materials, height, shape), access to and around the building (public transport, disability access, lifts, escalators), what resources the library should provide (archives, music, software, books) and what facilities the library should provide (galleries, theatres, cafes).

People consulted via written forms were also asked to comment on the existing Central Library and to detail the aspects of the library which they do and do not like. The data from these questions enabled the consultation officer to build up a deeper picture of what concerns both library users and non-users in their choice to use or not use the city centre library. The views of non-users were extremely important in the consultation as Birmingham Libraries wanted to take this opportunity to explore the factors which would encourage them to come in and use the library. The data can be used to reformulate existing services and resources, as well as to ensure that the Library of Birmingham meets its targets of increased user numbers.

Closed questions can be formulated after analysis of this initial stage of the consultation, using the key concerns and desires from the responses to the open question to provide categories of response.

\section{Consultation with adults}

The early decisions about methods and target groups and the creation of a standard set of consultation tools all proved to be essential to the smooth running of the consultation programme for adults in its early stages. For example, the postcard questionnaire was a success, as it could be left in a variety of venues for interested people to pick up, as well as be given out at consultation events, allowing people to provide their individual comments confidentially, as well as the comments they provided in discussion groups or interviews. To date 350 completed questionnaires have been returned from 10,000 produced, although not all of the 10,000 have been issued. The data collected via them has been extremely rich and detailed, often including long and detailed essay-like responses.

The decision to make use of existing groups and events also proved immensely successful, this being particularly true of groups which expressed an interest in being involved in the Library of Birmingham. Two examples of success are as follows:

1. The City Council runs a Sustainability Forum which meets 4-5 times per year, in which a different topic area is explored each meeting and real, practical solutions to the issues concerned are discussed and sought. Forum members requested a session to discuss the Library of Birmingham, specifically in relation to environmental issues. The architects and library staff gave a presentation and answered public questions and discussion groups examined sustainability issues, such as biodiversity, construction, energy, waste and 
accessibility. The results fed directly into the consultation findings and the architect's work on the concept design.

2. The Library of Birmingham consultation officer has been invited to a variety of local history group and readers' group meetings in community libraries across the city. As with the sustainability forum, the impetus for these sessions came from group members who were keen to learn more about the plans for the new library and who wanted to ensure that their views were heard.

Even where the group had not invited the Library of Birmingham team to consult, this kind of consultation session worked comparatively well, for example at various events run as part of Black History Month or the Birmingham Book Festival. Sessions which were set up specifically for the consultation did not provide as many people or as much information and were far less cost effective, involving significant amounts of staff time for little result. For example, three workshops to be held in the Central Library and including tours of the archive and special collections were badly attended despite wide publicity both within libraries and the local press. One of the workshops was cancelled and a total of 14 people attended the other two.

Library of Birmingham stands and stalls at informal city events were also an effective means to attract people to talk about their wishes from the Library of Birmingham. These worked best when staffed by people who were closely involved in the Library of Birmingham project, who could answer questions, provide accurate and up-to-date information and ascertain the views of people who stopped to talk. Two particularly successful such events were Artsfest, a weekend of free music and arts events in the city centre with market stalls for arts and culture organisations, and the City Centre Discovery Day, held on an August Sunday and opening up the city to its people via trails, tours of buildings and treasure hunts. Although both of these events were staff intensive, they were extremely successful in promoting the Library of Birmingham project and in seeking the views of people - in total approximately 500 people were consulted over the three days of these events. Other events where the Library of Birmingham had a stand of information and consultation tools but where staffing was either at a much lower level or non-existent, were not successful in generating written responses or comments.

All of the consultation events for adults have taken up significant time in planning, setting up, writing up and feeding back. Where library staff have been involved, this load has been a shared one, but the time taken in planning and follow-up has exceeded expectations, and the consultation officer has spent closer to a third than a half of her time in actual conversations with Birmingham's people. There has been a large amount of non-direct consultation work such as attending meetings with the architects and Library of Birmingham team and work which might be classified as marketing and promotion, for example in preparing presentations and publicity materials, in writing and distributing fact sheets about the Library of

Birmingham from the questions most asked in consultation, in updating the website pages and in keeping library staff across the service informed about the developments.

The work around the actual consultation itself has been vital to ensure that:

- the consultation events always include up-to-date information on the planning process

- $\quad$ the consultation events are marketed and promoted to target groups and thus well attended

- the consultation events are presented and written up professionally and thoroughly 
- $\quad$ the results are reliable and valid

- the results feed into the planning and design processes

- all library staff involved in the target group are informed, aware and involved in the consultation.

Although a vast amount of data has been collected from adults, there are target groups which have been consulted only peripherally to date. These groups have been harder to capture with the methods chosen and have fewer organised group meetings or organisations on which the Library of Birmingham consultation has been able to draw to support its work. Consequently, establishing consultation events for these groups has required additional planning and liaison with library departments and other council and local agencies. They will be targeted by the consultation officer between March and May 2003.

The consultation process itself has yielded predominantly positive ideas and suggestions for the Library of Birmingham, but there have been some negative responses and contradictory comments. The consultation process has had to emphasise that if there is a new library then it will be on the site chosen and significant time has been spent in describing the plans for the Eastside of the city, which many of the city's people do not know very well, and most people respond positively when they have more detail provided about the plans for the whole area. Furthermore, analysis and reporting has had to ensure that the balance of opinions and priorities are clearly stated. The quotes below illustrate some of the key concerns and suggestions of adults consulted to date:

"a much larger archive section with much more workspace and more staff"

"use must be free and opening hours generous"

"attractive exhibitions. Would like more computers there and more exciting things going on that would entertain you. Any book that I would like to take out I could"

"big open floors with huge windows and sky and trees and long horizon views"

"It would be more helpful if there would be more hilarious talking tapes available (such as Mr Bean and Goodness Gracious Me)"

"more access to more materials"

"architecture conducive to storage, access and use of textual materials, with smaller areas dedicated to visual, audio, and tactile materials"

"community facilities (café, picnic area, gallery, meeting rooms)"

"Soul.......... please not another soulless modern building like the current one"

"a building that is light, airy and easily accessible by public transport"

"green construction, roof garden, renewable energy and other features such as water saving technologies. This is a prestigious project for UK. It must lead the way in sustainable development"

"All the books and information all at the library, not in store somewhere in other parts of the city. More room on tables where you can spread papers out. The Shakespeare Room and old Spiral Staircase incorporated in the new building."

"'soft areas' for relaxing in" 
"An open space for local exhibitions, photographs, poems, etc. In fact entire floor for this".

\section{Consultation with children and young people}

Many of the challenges and problems of consultation for adults were reflected and magnified when consulting with children and young people. However, children were simpler to target and access as most 5-16 year olds are available in the captive setting of the school. Also children and young people tended to be extremely open-minded about libraries and their functions, imaginative about the possibilities for new types of services and facilities and creative in their thinking and expressions of their desires for a new city centre library. Children and young people responded much better to consultation when they were given information about the Library of Birmingham project (preferably orally), when they were in small to medium-sized groups and when they could provide their thoughts verbally. Some age-groups responded more positively than others, with teenage (13-16 year old) boys, in particular, being the hardest group to enthuse or elicit constructive comments from.

For example, the best consultation sessions with children and young people were visits by the consultation officer to schools where groups of 20-40 children had a 5-15 minute interactive talk about the library plans and were then asked to think about and say what they would like in a new city centre library. These worked best when the teacher or school librarian was also involved, in making suggestions, asking questions, providing disciplinary support or policing small children's visits to the lavatories! All school visits yielded three or four sides of flipchart paper covered in interesting ideas, suggestions and desires. They also yielded positive results for the library service in general, as children and teachers learnt about the free internet access, homework clubs, music resources and other facilities and services available in libraries now. The only drawback of this method was in the recording of responses, especially in groups where lots of ideas were shouted out in quick succession; only one actual quote was recorded from these groups, the rest of the responses being one-word, paraphrase or short hand versions of the exact words used by children and young people. Whilst this does not matter in relation to the overall findings of the consultation, it does leave the report 'thinner' in children's own words. The only way to effectively overcome this drawback would be to video the session. Most of these sessions lasted around 45-50 minutes and children and young people had a fantastically broad and diverse range of views about what a new city centre library should be like. In total, 250 children were spoken to in such settings in the autumn term, 2002.

Three other methods worked particularly well with children and young people.

1. A debate at the Young People's Parliament was attended by 153 children from a variety of city schools. The day consisted of introductions from Library Service staff and the architects about the Library of Birmingham, workshop sessions with the children on their desires and thoughts and a formal debate of the motion "This house believes that choosing a library building is as important as choosing the books to go in it".

2. Children who visited the Centre for the Child in the Central Library were asked to write or draw what they would like to see in a new city centre library and all suggestions were placed on the 'Wall of Wishes'. Staff posted four examples to kick-start the process and were available to discuss the children's ideas and questions. Additionally, many of the comments received in this way were mediated by parents or other carers who worked with their children to elicit the children's responses. 
3. Visits to non-school centres, such as youth clubs and sixth form colleges, talking to young people in small groups about their thoughts, suggestions and ideas.

The least successful method with children and young people, was asking them to state their desires for the new library in a written format but with little additional information, support or advice. For example, at the City Council's "looked-after children day", children were asked to record the things they like and the things they don't like about libraries and to state what they would like in a new city centre library. The responses to this were very limited, mainly one-word answers focusing on existing resources, particularly computers and books. These children did not have any information given to them about the plans and ideas for the Library of Birmingham, nor did they have the opportunity to discuss any queries with Library of Birmingham or children's team staff. Email responses are similarly mostly fairly 'thin' as are many of the 3,401 responses to a Library of Birmingham questionnaire included in the CIPFA Children's PLUS questionnaire. Despite these methods generally yielding less detailed information than discussion groups, they have provided some excellent quotes from children and young people about their desires and needs of the new library, as illustrated below:

"A council place where people can talk about their life"

"I would like the new library to have a theatre to show the very latest films"

"Crèche so that parents have time to choose their books or use the adult library"

"Some chairs if you have come here with heavy shopping"

"Really colourful and pretty"

"Interactive computer technology that allows you to read some of the book so it gives an idea of what its like"

"Somewhere to listen to music, watch TV or watch videos"

"I would like to have a garden in the library where I can sit and read my book or listen to the story-lady"

"I want people to say hello"

"I would like more children's books on religions like paganism and more poetry. I do like the library"

"Make a nicer building"

"A separate computer room within the children's library"

"A play ground"

"I would like the new library to have a bigger play area for big and small children. I would rather have more toilets"

"In the new library it would be nice to have comfy chairs or sofas to sit on; in a reading room which is peaceful; so that you can sit and read books. Also, the building could be brighter inside and out"

"I think there should be a cafertirlay (sic) for people to eat. There should be baby's areas and clubs and special days for races"

"Books that hang from the ceiling. More story and information books for children to read. More competitions. More games to choose to play on the computer". 


\section{Findings and how they fed into Richard Rogers Partnership design}

Over 1,400 people were consulted about the Library of Birmingham between July and November 2002, of which roughly one third were children and young people. Conclusions on the key desires for the new library were drawn from written comments and from records of discussion group comments.

From the findings of this initial consultation stage it is apparent that adults, children and young people share most key desires for a new city centre library. The six most commonly listed desires emerged from consultation with both adults and children and young people. These areas are:

1. An accessible building. The Library of Birmingham should be easy to get to using a variety of transport, but specifically it should be accessible by bus and within a ten minute walk from key bus, train and tram stops and car parks. The library should be in an attractive and safe external environment with other activities in the area to make it wellpopulated, busy and therefore safe and secure for pedestrians, especially after dark. Internally, the library should have an accessible layout, with stairs, lifts and escalators to move around the building, as well as clear signs and layout design. Facilities such as toilets and cloakrooms are also an essential aspect of accessibility.

2. An attractive and welcoming building. The Library of Birmingham should be an attractive building, which feels welcoming, approachable, relaxed and friendly. It should have good architecture and be a sustainable, green building. Internally, it should be light, spacious and airy with good décor, plants and water features.

3. A wide range of facilities and spaces. The Library of Birmingham should provide spaces and resources for a wide range of activities as well as formal learning. These spaces and facilities should include:

- performances, for example, poetry and book readings, theatre, storytelling

- exhibitions, such as photographic exhibitions, art galleries, local displays

- community spaces, such as meeting rooms

- social spaces, such as cafes and other eating places, areas for discussions, places to sit and relax with comfortable seating.

For children and young people, separate spaces dedicated to their own age group was also important - the feeling of having a 'place of our own'. Spaces in or around the library for sports activities were also important for children and young people.

4. Computers to support both learning and entertainment. The Library of Birmingham should have plentiful computers which can be used for standard applications, such as word-processing and spreadsheets, so that people can work in the library. The computers should also have high speed internet connections and be as up-to-date as possible. For children and young people, computer applications for entertainment and for borrowing from the library were also important.

5. Quiet study spaces to support learning. The Library of Birmingham should support all people in their learning by ensuring that there are places in the new Library for quiet, peaceful work. Quiet study areas must have adequate desk and chair resources and be near to key resource collections. For children and young people, it was also essential that the Library of Birmingham provide areas for study where group discussions could take place and where it was acceptable to listen to music. 
6. Wide range of accessible resources. Existing resource collections such as books, CDs, DVDs, newspapers, magazines, journals should be maintained and expanded in the Library of Birmingham. More of the collections currently available as reference resources only should be available on loan.

Three other desires which had less emphasis but featured in both adult and/or children and young people's comments were improved opening hours, improved archives and improved search facilities, including links to other local and regional library catalogues.

The initial concept design has been created to take these desires into account where possible. For example, the architects have worked with environmental engineers to ensure that the building is sustainable, uses minimum fuel resources, encourages diversity in the local flora and fauna and recycles and reuses water. Similarly, the building has been designed to maximise the use of natural light for library users whilst protecting its resources. Some of the key desires are not within the architect's direct remit at this stage, such as the resources and facilities which are housed within the library or the ICT resources. Nevertheless, these desires have been fed into the planning and the initial designs ensure enough space and flexibility for increased space for exhibitions, performances and meetings, for example.

\section{Next stages}

Between March and May 2003 the consultation programme will continue to concentrate on seeking the views of Birmingham's people. Specifically, groups such as under-5 years olds, children with disabilities, the business community and black and minority ethnic communities, will be targeted, as these have so far not been adequately covered by the programme. Consultation with local, regional and national users and potential users of the city's archives and historic collections will also be prioritised, to feed into a bid to the Heritage Lottery Fund for funds to develop these collections in the Library of Birmingham.

May and June will be spent bringing together the findings of all the consultation activities and events held over the year into a final report. A consultation programme for Birmingham Libraries will also be developed to ensure that the ongoing development of the Library of Birmingham over the next 4-5 years takes into account the wishes and ideas of the city's people. The current plans are that the Library of Birmingham will open in early 2008 and the consultation must continue until that time and beyond - a period of public evaluation is essential to ensure the new library is meeting needs and to make necessary changes.

\section{Conclusions}

The initial consultation on the Library of Birmingham has demonstrated the value of employing a broad range of tools, methods and venues to ensure wide involvement of the city's population, both library users and non-users. A selection of basic publicity materials, written questionnaires and simple standard questions enabled a consistent approach to the consultation to be taken across all groups consulted. This simple set of questions were open and broad thus providing great depth of detail in the response, without prompting potential answers. The data received has been extremely high quality and has proved invaluable in informing the concept design and ongoing development work on the Library of Birmingham.

The consultation officer has been completely immersed in the Library of Birmingham project and this has been necessary in order to both inform the public and to seek their views successfully. Accurate and up-to-date information is essential in consultation with such a fast-developing project and the consultation officer role has included a significant amount of 
promotion, information and marketing work. This work and that involved in the planning, analysis and writing up of consultation, whilst essential for success, has meant that around a third of the officer's time has been spent in direct liaison with the public, in comparison with an initial estimate of half of her time.

Successful consultation for this project has been rooted in the use of a variety of tools and methods. The most successful consultation methods with adults have been a postcard questionnaire distributed via community libraries, other venues and at cultural events and sessions with interested groups such as local history and reader groups. For children and young people, the most successful methods have been sessions with groups in schools, colleges and youth clubs and the Young People's Parliament debate and workshops. Children and young people in particular have proved themselves to be very open and imaginative, and a rich picture of their future vision for libraries has been built up.

Overall, the early consultation has been successful and extremely positive both in promoting the existing library services, in informing the public about the Library of Birmingham project and in securing useful data. The next stages need to build on this work and to target the harder-to-reach communities to ensure a balanced, city-wide spread of voices are heard in the development of this exciting new Library of Birmingham.

\section{Reference}

Dolan, J and Khan, A. The Library of Birmingham, Library and Information Update, August 2002 (http://www.cilip.org.uk/update/issues/aug02/article3aug.html) 